\title{
Impact of COVID-19 on stroke admissions, treatments, and outcomes at a comprehensive stroke centre in the United Kingdom
}

\author{
Nishita Padmanabhan ${ }^{1,2}$ (D) Indira Natarajan ${ }^{1} \cdot$ Rachel Gunston $^{1} \cdot$ Marko Raseta $^{3} \cdot$ Christine Roffe $^{1,2}$
}

Received: 19 August 2020 / Accepted: 25 September 2020 / Published online: 6 October 2020

(C) The Author(s) 2020

\begin{abstract}
Introduction The coronavirus disease (COVID-19) pandemic has changed routine clinical practice worldwide with major impacts on the provision of care and treatment for stroke patients.

Methods This retrospective observational study included all patients admitted to the Royal Stoke University Hospital in Stokeon-Trent, UK, with a stroke or transient ischaemic attack between March 15th and April 14th, 2020 (COVID). Patient demographics, characteristics of the stroke, treatment details and logistics were compared with patients admitted in the corresponding weeks in the year before (2019).

Results There was a 39.5\% ( $n=101$ vs $n=167)$ reduction in admissions in the COVID cohort compared with 2019 with more severe strokes (median National Institutes of Health Stroke Scale (NIHSS) 7 vs 4, $p=0.02$ ), and fewer strokes with no visible acute pathology $(21.8$ vs $37.1 \%, p=0.01)$ on computed tomography. There was no statistically significant difference in the rates of thrombolysis $(10.9 \mathrm{vs} 13.2 \%, p=0.72)$ and/or thrombectomy $(5.9 \mathrm{vs} 4.8 \%, p=0.90)$ and no statistically significant difference in time from stroke onset to arrival at hospital (734 vs $576 \mathrm{~min}, p=0.34$ ), door-to-needle time for thrombolysis ( 54 vs $64 \mathrm{~min}, p=$ 0.43 ) and door-to-thrombectomy time (181 vs $445 \mathrm{~min}, \mathrm{p}=0.72)$. Thirty-day mortality was not significantly higher in the COVID year (10.9 vs $8.9 \%, p=0.77)$. None of the 7 stroke patients infected with COVID-19 died.

Conclusions During the COVID-19 pandemic, the number of stroke admissions fell, and stroke severity increased. There was no statistically significant change in the delivery of thrombolysis and mechanical thrombectomy and no increase in mortality.
\end{abstract}

Keywords Stroke $\cdot$ COVID-19 $\cdot$ Thrombolysis $\cdot$ Thrombectomy $\cdot$ Infarct $\cdot$ Mortality

Nishita Padmanabhan

nishita.padmanabhan@uhnm.nhs.uk

Indira Natarajan

indira.natarajan@uhnm.nhs.uk

Rachel Gunston

rachel.gunston@uhnm.nhs.uk

Marko Raseta

m.raseta@erasmusmc.nl

Christine Roffe

christine.roffe@uhnm.nhs.uk

1 Neurosciences, Royal Stoke University Hospital, Stoke-on-Trent, UK

2 Faculty of Medicine and Health Sciences, Keele University, Staffordshire, UK

3 Statistics and Mathematical Modelling, Department of Molecular Genetics, Erasmus MC, Rotterdam, Netherlands

\section{Introduction}

Coronavirus disease 2019 (COVID-19) is an infectious disease caused by the SARS-CoV-2 virus. As of September 21 st, 2020, there are 30,675,675 confirmed COVID-19 cases and 954,417 confirmed deaths in over 216 countries/territories worldwide [1]. The United Kingdom (UK), with 390,362 confirmed cases and 41,759 confirmed deaths, continues to have community transmission at present [1]. COVID-19 is associated with a hypercoagulable state that may lead to an increase in acute cerebrovascular events with an increase in ischaemic strokes and large vessel occlusion strokes [2-4]. Preliminary global reports show a reduction in the number of stroke admissions with a delay in the presentation of acute ischaemic strokes and time to thrombolysis and thrombectomy [5-7].

The response to the coronavirus disease (COVID-19) pandemic saw organisations across the UK using varied strategies to approach changes in routine clinical practice. The Hyper Acute Stroke Unit in the Royal Stoke University Hospital also 
adopted a new model. Outpatient clinics with direct patient contact were closed and replaced by virtual clinics. All holidays, study leave and non-clinical activity were cancelled, thereby increasing the shop floor presence of nursing and medical workforce. The junior doctor schedule was changed from the standard 9 am to $5 \mathrm{pm}$ working hours to a more widely distributed $24 \mathrm{~h}$ round the clock availability on the ward with reduced additional speciality responsibilities.

The UK went into lockdown on March 23rd, 2020, and the COVID-19 pandemic began in Stoke-on-Trent in the West Midlands around March 15th, 2020. Our study aimed to establish whether and how the delivery of stroke care during this period was affected by the COVID-19 pandemic. We did this by comparing 4 weeks when we had the highest number of COVID-19 cases in 2020 with the same period in the year before. The aim of this was to see whether there were any changes to the number of stroke unit admissions in the COVID year.

\section{Methods}

\section{Study design and setting}

This retrospective observational study was based at the Hyper Acute Stroke Unit (HASU) in the Royal Stoke University Hospital, Stoke-on-Trent, UK. The 32-bedded comprehensive tertiary stroke centre at the Royal Stoke University Hospital in Stoke-on-Trent caters to a local population of half a million individuals. We receive secondary referrals from three district general hospitals and tertiary referrals for mechanical thrombectomy from four acute stroke units. Situated in a region with a high prevalence of vascular co-morbidity due to high unemployment, the unit has a secondary catchment area of 1.5 million and a tertiary catchment area of 3 million with around 1250 stroke admissions every year.

Two cohorts were identified for this study from local Sentinel Stroke National Audit Programme data. The Sentinel Stroke National Audit Programme database records all patients admitted to the hospital with a stroke diagnosis. This includes patients who are not admitted to the Hyper Acute Stroke Unit. Cohort 1 (COVID) included all patients admitted to the hospital during the first 4 weeks of the COVID-19 pandemic with a diagnosis of stroke/stroke mimic/transient ischaemic attack (TIA), i.e. between March 15th and April 14th, 2020. All patients admitted with a stroke received care on the Hyper Acute Stroke Unit during this period. Cohort 2 (pre-COVID) included all patients admitted to the hospital during the corresponding weeks in the previous year, i.e. between March 15th and April 14th, 2019. Patients who were not admitted with a diagnosis of stroke/TIA/stroke mimic were excluded.

\section{Data collection}

Data on patient demographics, characteristics of stroke, the time between onset and hospital presentation, treatment details and outcomes were included in this study analysis. Data were extracted from the local Sentinel Stroke National Audit Programme database and from the hospital's electronic health records system. This includes discharge letters, blood results and imaging results. The ward admissions' book and patient notes were also accessed to gather information.

\section{Plan of analysis/statistical tools}

Data was entered and summarised in Microsoft Excel. Categorical variables were compared by means of $Z$ test (binary variables), Chi-squared test (categorical variables with 3 or more categories) and Fisher's exact test (low expected percell observations). The Kolmogorov-Smirnov test was used to assess normality of continuous variables (age, National Institutes for Health Stroke Scale (NIHSS) score and timings) which were subsequently compared using Student $t$ test or Mann-Whitney $U$ test for normally distributed and nonnormal data, respectively. Statistical analysis was done in $\mathrm{R}$ statistical software tool (R Core Team, 2018). Significance was accepted at $p<0.05$.

\section{Results}

There were 101 and 167 admissions with stroke/TIA/stroke mimic in the COVID cohort and the pre-COVID cohort, respectively, representing $39.5 \%$ fewer admissions during the COVID pandemic peak (Table 1). In the COVID cohort, 7 (6.9\%) were positive for SARS-CoV-2 virus on polymerase chain reaction testing. No tests were done in 2019 (Table 1). The mean age of patients was 70.4 SD 14.9/73.2 SD 13.8 years in the COVID and pre-COVID cohorts, with just under 50\% females (47.5 vs $49.1 \%)$ and a high proportion of White ethnicity ( 90.1 vs $88.6 \%$ ). There was no statistically significant difference in any of these characteristics between the two cohorts (Table 2).

Table 1 Comparison of stroke admissions during COVID year and preCOVID year

\begin{tabular}{lll}
\hline & COVID & Pre-COVID \\
\hline Number of stroke admissions & 101 & 167 \\
COVID-19 positive $(n(\%))$ & $7(6.9 \%)$ & N/A \\
COVID-19 mortality $(n(\%))$ & $0(0.0 \%)$ & N/A \\
\hline
\end{tabular}

$n$, number of patients 
Table 2 Demographic details of stroke admissions in the COVID and pre-COVID cohorts

\begin{tabular}{lccc}
\hline Demographics & COVID $(n=101)$ & Pre-COVID $(n=167)$ & $p$ value \\
\hline Age mean (SD) & $70.4(14.9)$ & $73.2(13.8)$ & $0.13^{\mathrm{a}}$ \\
Female sex $(n(\%))$ & $48(47.5 \%)$ & $82(49.1 \%)$ & $0.90^{\mathrm{b}}$ \\
Ethnicity White $(n(\%))$ & $91(90.1 \%)$ & $148(88.6 \%)$ & $0.86^{\mathrm{b}}$ \\
Ethnicity Non-White/not specified $(n(\%))$ & $10(9.9 \%)$ & $19(11.4 \%)$ & \\
\hline
\end{tabular}

$n$, number of patients; $S D$, standard deviation

${ }^{\mathrm{a}} t$ test

${ }^{\mathrm{b}} Z$ test

The final diagnosis was stroke (ischaemic or haemorrhagic) in $92(91.1 \%) / 145(86.8 \%)$, transient ischemic attack in $0(0 \%) / 2(1.2 \%)$ and stroke mimic in $9(8.9 \%) / 20$ $(12.0 \%)$ in the COVID and pre-COVID cohorts, respectively. Among the strokes, $70(69.4 \%) / 121$ (72.2\%) were ischaemic, and $22(21.8 \%) / 24(14.4 \%)$ were haemorrhagic in the two respective cohorts. None of the differences was statistically significant (Table 3).

Stroke severity was significantly higher in the COVID cohort than in the pre-COVID cohort (median (IQR) NIHSS 7 $(3-16)$ vs $4(2-12), p=0.02)$. Significantly fewer patients had no acute findings (ischaemia or haemorrhage) on imaging in the COVID cohort than pre-COVID (22 $(21.8 \%)$ vs 62 $(37.1 \%), p=0.01)($ Table 3$)$.
There were no statistically significant differences in the rates of thrombolysis $(11(10.9 \%)$ vs $22(13.2 \%))$ and mechanical thrombectomy (6 (5.9\%) vs $8(4.8 \%)$ ) between the COVID and pre-COVID cohorts. Moreover, no statistically significant difference was found between cohorts in the time from onset to hospital arrival (median 734 vs $576 \mathrm{~min}$ ), door to thrombolysis time (mean $54 \mathrm{vs} 64 \mathrm{~min}$ ) and door to groin time for mechanical thrombectomy (mean 181 vs $445 \mathrm{~min}$ ) (Table 4).

Thirty-day mortality was similar between the COVID and pre-COVID cohorts (11 (10.9\%) vs 15 (8.9\%), $p=$ 0.77). There were no deaths among COVID-positive patients, and there was no statistically significant difference in stroke recurrence (4 $(3.9 \%)$ vs $13(7.8 \%), p=$
Table 3 Characteristics of stroke in the COVID and pre-COVID cohorts

\begin{tabular}{llcl}
\hline$n(\%)$ except where indicated & COVID $(n=101)$ & Pre-COVID $(n=167)$ & $p$ value \\
\hline Final diagnosis & & & \\
Stroke (ischemic or haemorrhagic) & $92(91.1 \%)$ & $145(86.8 \%)$ & $0.39^{\mathrm{a}}$ \\
Transient ischaemic attack & $0(0 \%)$ & $2(1.2 \%)$ & $0.53^{\mathrm{d}}$ \\
Stroke mimic & $9(8.9 \%)$ & $20(12.0 \%)$ & $0.56^{\mathrm{a}}$ \\
Radiological findings & & & \\
Visible acute infarct on imaging & $57(56.4 \%)$ & $81(48.5 \%)$ & $0.26^{\mathrm{a}}$ \\
Primary intracerebral haemorrhage & $22(21.8 \%)$ & $24(14.4 \%)$ & $0.16^{\mathrm{a}}$ \\
No acute ischemia or haemorrhage & $22(21.8 \%)$ & $62(37.1 \%)$ & $0.01^{\mathrm{a}}$ \\
Stroke severity & & $4(2-12)$ & $0.02^{\mathrm{b}}$ \\
NIHSS (median (IQR)) & $7(3-16)$ & $71(42.5 \%)$ & $0.14^{\mathrm{c}}$ \\
Mild stroke (NIHSS 0-3) & $31(30.7 \%)$ & $43(25.8 \%)$ & \\
Moderate stroke (NIHSS 4-8) & $27(26.7 \%)$ & $53(31.7 \%)$ & \\
Severe stroke (NIHSS >8) & $43(42.6 \%)$ & & $0.87^{\mathrm{a}}$ \\
Bamford classification & & $32(19.1 \%)$ & $0.28^{\mathrm{a}}$ \\
Total anterior circulation infarct & $21(20.8 \%)$ & $35(20.9 \%)$ & $0.38^{\mathrm{a}}$ \\
Partial anterior circulation infract & $15(14.9 \%)$ & $44(26.3 \%)$ & $0.08^{\mathrm{a}}$ \\
Lacunar infarct & $21(20.8 \%)$ & $10(5.9 \%)$ & $0.16^{\mathrm{a}}$ \\
Posterior circulation infarct & $13(12.9 \%)$ & $24(14.4 \%)$ & \\
Haemorrhagic stroke & $22(21.8 \%)$ & &
\end{tabular}

$I Q R$, interquartile range; $n$, number of patients; NIHSS, National Institutes of Health Stroke Scale

${ }^{\mathrm{a}} Z$ test

${ }^{\mathrm{b}}$ Mann-Whitney $U$ test

${ }^{\mathrm{c}}$ Chi-squared test

${ }^{\mathrm{d}}$ Fisher's exact test 
Table 4 Impact of COVID-19 on frequency and timing of thrombolysis and mechanical thrombectomy

\begin{tabular}{lccc}
\hline & COVID $(n=101)$ & Pre-COVID $(n=167)$ & $p$ value \\
\hline Thrombolysis $(n(\%))$ & $11(10.9 \%)$ & $22(13.2 \%)$ & $0.72^{\mathrm{a}}$ \\
Mechanical thrombectomy $(n(\%))$ & $6(5.9 \%)$ & $8(4.8 \%)$ & $0.90^{\mathrm{a}}$ \\
Time from onset to arrival (median (IQR)) min & $734(246-1091)$ & $576(128-1197)$ & $0.34^{\mathrm{b}}$ \\
Time from arrival to thrombolysis (mean SD) min & $54(30)$ & $64(47)$ & $0.43^{\mathrm{c}}$ \\
Time from arrival to thrombectomy (mean SD) min & $181(62)$ & $445(566)$ & $0.72^{\mathrm{c}}$ \\
\hline
\end{tabular}

$\mathrm{IQR}=$ interquartile range; $\mathrm{n}=$ number of patients; $\mathrm{SD}=$ standard deviation

${ }^{\mathrm{a}} Z$ test

${ }^{\mathrm{b}}$ Mann-Whitney $U$ test

${ }^{\mathrm{c}} t$ test
0.32 ) and discharge destination between the cohorts (Table 5).

\section{Discussion}

The key findings of this project are a reduction in the total number of stroke admissions and an increase in stroke severity during the COVID-19 pandemic. There was no statistically significant change in the rates and timings of delivery of thrombolysis and mechanical thrombectomy, and no worsening of stroke outcomes during the pandemic.

During the same time periods, the West Midlands Ambulance Service University NHS Foundation Trust Ambulance Service, which covers the Royal Stoke University Hospital and the wider West Midlands region, reported no reduction in callouts for stroke [8]. While this data suggests that the same number of people are calling 999 with acute stroke symptoms, fewer are admitted with a diagnosis of stroke. It is possible that patients with milder symptoms were treated on-site rather than taken to the hospital. We have no details to confirm this. However, our observation of greater stroke severity in admitted patients lends some support to this possibility. Patients who did not present to the hospital were not captured as there is no community stroke registry.
Fewer callouts resulting in a transfer to a hospital may have been due to national guidance to avoid hospital admission, wherever possible, or because of patients refusing transfer to hospital because of fear of COVID-19. Rudilosso et al. report an increase in daily emergency phone calls with a fall in the number of stroke admissions during their COVID peak in Barcelona [9]. In contrast, teams from Seville and Ohio report significant decreases in their daily stroke alerts and telephone stroke consultations $[5,10]$. The reason for these differences between centres is not apparent. Zhao et al. report a significant drop in the hospital admissions for stroke during COVID-19 pandemic in China [11]. A multicentre study by Hoyer et al. in Germany reports a significant reduction in acute stroke and TIA admissions following the implementation of national lockdown and decreased public mobility [12].

In our cohort, stroke patients presented with a higher median NIHSS with no statistically significant difference in the stroke demographics, i.e. age, sex and ethnicity. This is different from Rudilosso et al., who report younger strokes, but no difference in severity at presentation [9].

We did not find a significant increase in the time between symptom onset and arrival at the hospital. This mirrors findings from Ohio and Barcelona [5, 9]. However, Schirmer et al. and Montaner et al. describe a significant increase in stroke onset time to arrival at the hospital during the COVID-19
Table 5 Impact of COVID-19 on stroke outcome

\begin{tabular}{lccc}
\hline Outcome $n(\%)$ & COVID $(n=101)$ & Pre-COVID $n=167$ & $p$ value \\
\hline 30-day mortality & $11(10.9 \%)$ & $15(8.9 \%)$ & $0.77^{\mathrm{a}}$ \\
Stroke recurrence & $4(3.9 \%)$ & $13(7.8 \%)$ & $0.32^{\mathrm{a}}$ \\
Discharged to home/care home & $59(58.4 \%)$ & $106(63.5 \%)$ & $0.28^{\mathrm{b}}$ \\
Discharged to another acute setting & $17(16.8 \%)$ & $36(21.5 \%)$ & \\
Discharged to an inpatient rehabilitation centre & $15(14.9 \%)$ & $14(8.4 \%)$ & \\
Death during hospital stay & $10(9.9 \%)$ & $11(6.6 \%)$ & \\
\hline
\end{tabular}

$n$, number of patients

${ }^{\mathrm{a}} Z$ test

${ }^{\mathrm{b}} 2 \mathrm{x} 4$ Chi-squared test 
period for a collaboration of 12 hospitals in 6 states in the USA and Seville in Spain, respectively $[6,10]$. This is similar to Frisullo et al., who reported a significant increase in the onset-to-door time in the early phase of the pandemic in Rome [13]. Such differences may reflect different policies in prioritisation of stroke transfer and/or differing strain on existing services due to high numbers of COVID-19 patients.

In our study, neither the proportion of patients treated with thrombolysis and/or thrombectomy nor the timeliness of interventions differed significantly to the year before the COVID pandemic. However, numbers were small, making point estimates imprecise. Lower rates of intravenous thrombolysis and thrombectomy were reported from Spain and China where their health services were overrun [9-11]. A study conducted in France showed significant delays between imaging and groin puncture timings during the COVID-19 period. However, this difference was not significant when patients underwent thrombectomy at the first hospital that they presented to [7]. A study of 17 thrombectomy centres in Europe, Canada and the USA showed a significant decrease in the number of thrombectomies performed and an increase in stroke onset-to groin puncture after confinement measures were put in place [14].

In the UK, the medical service was not overwhelmed, but we did have higher mortality in the COVID year. A pooled analysis by Aggarwal shows increased odds of severe cerebrovascular disease in COVID-19-infected patients [15]. This is unlike our experience. Stroke mortality has not increased despite greater severity, and there was no statistically significant change in outcomes at discharge. We have been able to maintain quality care with comparable outcomes and without significant mortality.

It can be hypothesised that a lower number of stroke admissions allowed us to provide a better service to the individual. In addition, cancellation of all non-clinical tasks, annual and study leave compensated for staff absences through COVID-19 infection and quarantine, freed up consultant time and increased consultant presence on the ward. Junior doctor workforce was more evenly distributed throughout the 24 hours, and this may have allowed for earlier detection and treatment of complications. The greater presence of medical staff translated to lower threshold for nurses to contact doctors of all grades for advice which led to focussed assessments and improved patient care. While service was provided as usual for patients who presented to the hospital, secondary prevention may have been missed out for patients who did not present themselves. For future pandemics, this needs to be managed proactively by raising public awareness, liaison with ambulance services, and general practitioners, and the provision of 'catch-up' services to maintain secondary prevention and prevent avoidable strokes.

Locally, the change in number and severity of stroke patients prompted a public awareness campaign via local Stoke-
on-Trent news and radio interviews during the month of May highlighting concerns over the drop in stroke admissions in our region and advising the public to seek help from the National Health Service (NHS) if they experience symptoms of a stroke [16]. There was a special focus on people with minor stroke symptoms and elderly isolated patients. A week later, the National Health Service 'Help Us Help You' campaign by the British Government also urged the public to continue to act FAST (face, arms, speech, time) by calling 999 for stroke symptoms [17].

The main limitation of our study is that it is from a single hospital. Numbers are therefore too small to detect small, but potentially important differences reliably. It will be important to see whether our findings are reflected elsewhere in the UK and whether the trend of admissions is due to fewer patients presenting, or fewer patients who call 999 being admitted to hospital.

\section{Conclusion}

We provide evidence that stroke admissions have reduced by two-fifths during the COVID-19 pandemic, but that admitted stroke patients had greater neurological deficits. Rate of delivery of hyperacute interventions such as thrombolysis and mechanical thrombectomy was unchanged, and there was no increase in mortality or adverse discharge outcomes. Our findings contribute to the knowledge base of the effect of service changes on outcomes in times of exceptional stress on the health system.

Data availability The datasets analysed during the current study are available from the corresponding author on reasonable request.

\section{Compliance with ethical standards}

Conflict of interest The authors declare that they have no conflict of interest.

Ethical approval This is an audit of the effect of COVID-19 on service provision for stroke at our hospital. Data for this project were collected as part of the Sentinel Stroke Audit Programme (SSNAP), which is approved by the NHS Health Research Authority (HRA). All data included are anonymized. Patients were not asked to give informed consent.

Open Access This article is licensed under a Creative Commons Attribution 4.0 International License, which permits use, sharing, adaptation, distribution and reproduction in any medium or format, as long as you give appropriate credit to the original author(s) and the source, provide a link to the Creative Commons licence, and indicate if changes were made. The images or other third party material in this article are included in the article's Creative Commons licence, unless indicated otherwise in a credit line to the material. If material is not included in the article's Creative Commons licence and your intended use is not permitted by statutory regulation or exceeds the permitted use, you will need to obtain permission directly from the copyright holder. To view a copy of this licence, visit http://creativecommons.org/licenses/by/4.0/. 


\section{References}

1. World Health Organisation. Coronavirus disease (COVID-2019) weekly epidemiological update - 21 September 2020. Available on https://www.who.int/emergencies/diseases/novel-coronavirus2019/situation-reports. Accessed 22 Sept 2020

2. Ellul MA, Benjamin L, Singh B, et al. (2020) Neurological associations of COVID-19. Lancet Neurol, Published Online July 2nd, 2020. https://doi.org/10.1016/S1474-4422(20)30221-0

3. Kihira S, Schefflein J, Mahmoudi K et al (2021) Association of coronavirus disease (COVID-19) with large vessel occlusion strokes: a case-control study. AJR 216:1-6. https://doi.org/10. 2214/AJR.20.23847

4. Helms J, Kremer S, Merdji H et al (2020) Neurologic features in severe SARS-CoV-2 infection. N Engl J Med. https://doi.org/10. 1056/NEJMc2008597

5. Uchino K, Kolikonda MK, Brown D, Kovi S, Collins D, Khawaja Z, Buletko AB, Russman AN, Hussain MS (2020) Decline in stroke presentations during COVID-19 surge. Stroke. 51:00-00. https:// doi.org/10.1161/STROKEAHA.120.030331

6. Schirmer CM, Ringer AJ, Arthur AS et al (2020) Delayed presentation of acute ischemic strokes during the COVID-19 crisis. J Neurointervent Surg 12:639-642. https://doi.org/10.1136/ neurintsurg-2020-016299

7. Kerleroux B, Fabacher T, Bricout N, Moïse M, Testud B, Vingadassalom S, Ifergan H, Janot K, Consoli A, Ben Hassen W, Shotar E, Ognard J, Charbonnier G, L'Allinec V, Guédon A, Bolognini F, Marnat G, Forestier G, Rouchaud A, Pop R, Raynaud N, Zhu F, Cortese J, Chalumeau V, Berge J, Escalard S, Boulouis G, Chivot C, Hanafi R, Pasco A, Girot JB, Biondi A, di Caterino F, Primikiris P, Vitale G, Bonnet L, Gariel F, Barreau X, Debruxelles S, Lucas L, Menegon P, Olindo S, Poli M, Renou P, Sagnier S, Sibon I, Veunac L, Gentric JC, Barbier C, Boulanger M, Cogez J, Guettier S, Schneckenburger R, Touze E, Delaitre M, Lebendinsky P, Musacchio M, Ricolfi F, Thouant P, Caparros F, Casolla B, Della Schiava L, Dequatre N, Henon H, Pasi M, Kazemi A, Bala F, Estrade L, Mounayer C, Saleme S, Macian-Montoro F, Eker O, Cotton F, Blanc-Lasserre K, Cakmak S, Cho TH, Derex L, Lukaszewicz AC, Mechtouff L, Nighoghossian N, Philippeau F, Riva R, Turjman F, Vallet AE, Carle X, Dory-Lautrec P, Reyre A, Hak JF, Brunel H, Benali A, Collemiche FL, Dargazanli C, Cagnazzo F, Derraz I, Arquizan C, Corti L, Costalat V, Gaillard N, Gascou G, Lefèvre PH, Mourand I, Riquelme C, Derelle AL, Gory B, Liao L, Tonnelet R, Anxionnat R, Bonnerot M, Bracard S, Braun M, Humbertjean L, Lacour JC, Mione G, Planel S, Richard S, Riou-Comte N, Schmitt E, Bourcier R, Detraz L, Desal H, Alexandre PL, Daumas-Duport B, Lenoble C, Roy M, Coskun O, di Maria F, Lapergue B, Rodesch G, Wang A, Weisenburger-Lile D, Zimatore S, Ajili N, Buard G, Evrard S, Gorza L, Gratieux J, Leguen M, Marinier S, Pico F, Poll R, Rakotoharinandrasana H, Tassan P, Tchikviladze M, Delvoye F, Hebert S, Blanc R, Ciccio G, Desilles JP, Maier B, Mazighi M, Piotin M, Redjem H, Smajda S, Ben Maacha M, Corabianu O, de Broucker T, Ille O, Manchon E, Obadia M, Obadia M, Raynouard I, Peres R, Sabben C, Smadja D, Taylor G, Thion LA, Lecler A, Spelle L, Denier C, Caroff J, Chassin O, Spelle, Venditti L, Aymard A, Betty J, Civelli V, Eliezer M, Fantoni M, Houdart E, Labeyrie MA, Saint Maurice JP, Kalsoum E, Pacini A, Ramadane C, Tuilier T, Villain A, Clarencon F, Degos V, Elhfnawy A, Elhorany M, Lenck S, Premat K, Sourour NA, Alamowitch S, Baronnet F, Crozier S, Deltour S, Leger A, Rosso C, Deltour S, Leger A, Rosso C, Pyatigorskaya N, Rodriguez Regent C, Trystram D, Naggara O, Seners P, Turc G, Edjlali M, Agbonon R, Alotaibi M, Sonchet A,
Oppenheim C, Meder JF, Benzakoun J, Legrand L, Fauché C, Velasco S, Manceau PF, Moulin SSS, Eugene F, Ferre JC, Paya C, Eugene F, Gauvrit JY, Langnier-Lemercier S, Lassale M, Raoult, Ronziere, Tracol C, Vannier S, Burel J, le Moal J, Papagiannaki C, Aggour M, Sachet M, Boutet C, Beaujeux R, Hasiu A, Manisor M, Mihoc D, Kremer S, Arteaga C, Gazzola S, Darcourt J, Cognard C, Bonneville F, Christine Januel A, Olivot JM, Raposo N, Viguier A, Bibi R, Boustia F, Herbreteau D, Maldonado I, Narata AP (2020) Mechanical thrombectomy for acute ischemic stroke amid the COVID-19 outbreak. Stroke 51: 2012-2017. https://doi.org/10.1161/STROKEAHA.120.030373

8. Holmes JL, Brake S, Docherty M, Lilford R, Watson S (2020) Emergency ambulance services for heart attack and stroke during UK's COVID-19 lockdown. Lancet 395:e93-e94. https://doi.org/ 10.1016/S0140-6736(20)31031-X

9. Rudilosso S, Laredo C, Vera V, et al. (2020) Acute stroke care is at risk in the era of COVID-19: experience at a comprehensive stroke center in Barcelona [published online ahead of print, May 22nd, 2020]. Stroke, STROKEAHA120030329. https://doi.org/10.1161/ STROKEAHA.120.030329

10. Montaner J, Barragán-Prieto A, Pérez-Sánchez S, et al. (2020) Break in the stroke chain of survival due to COVID-19. Stroke, STROKEAHA 120030106 . https://doi.org/10.1161/ STROKEAHA.120.030106

11. Zhao J, Li H, Kung D, Fisher M, Shen Y, Liu R (2020) The impact of the COVID-19 epidemic on stroke care and potential solutions. Stroke 51:1996-2001. https://doi.org/10.1161/STROKEAHA.120. 030225

12. Hoyer C, Ebert A, Huttner HB, Puetz V, Kallmünzer B, Barlinn K, Haverkamp C, Harloff A, Brich J, Platten M, Szabo K (2020) Acute stroke in times of the COVID-19 pandemic. Stroke 51:2224-2227. https://doi.org/10.1161/STROKEAHA.120.030395

13. Frisullo G, Brunetti V, Di Iorio R et al (2020) Effect of lockdown on the management of ischemic stroke: an Italian experience from a COVID hospital. Neurol Sci 41:2309-2313. https://doi.org/10. 1007/s10072-020-04545-9

14. Hajdu SD, Pittet V, Puccinelli F, Ben Hassen W, Ben Maacha M, Blanc R, Bracco S, Broocks G, Bartolini B, Casseri T, Clarençon F, Naggara $\mathrm{O}$, Eugène $\mathrm{F}$, Ferré JC, Guédon $\mathrm{A}$, Houdart E, Krings T, Lehmann P, Limbucci N, Machi P, Macho J, Mandruzzato N, Nappini S, Nawka MT, Nicholson P, Marto JP, Pereira V, Correia MA, Pinho-e-Melo T, Nuno Ramos J, Raz E, Ferreira P, Reis J, Shapiro M, Shotar E, van Horn N, Piotin M, Saliou G (2020) Acute stroke management during the COVID-19 pandemic: does confinement impact eligibility for endovascular therapy? Stroke 51(8): 2593-2596. https://doi.org/10.1161/STROKEAHA.120.030794

15. Aggarwal G, Lippi G, Michael Henry B (2020) Cerebrovascular disease is associated with an increased disease severity in patients with coronavirus disease 2019 (COVID-19): a pooled analysis of published literature. Int J Stroke 15(4):385-389. https://doi.org/10. $1177 / 1747493020921664$

16. Natarajan I (2020) Stroke concerns as numbers attending take a big dip during pandemic. University Hospitals of North Midlands NHS Trust News; 07 May 2020. https://www.uhnm.nhs.uk/latest-uhnmnews/posts/2020/may/stroke-concerns-as-numbers-attending-takea-big-dip-during-pandemic/ Accessed 15 Sept 2020

17. Public told 'act FAST' as NHS uses artificial intelligence to speed up stroke care. NHS News; 14 May 2020. https://www.england. nhs.uk/2020/05/public-told-act-fast-as-nhs-uses-ai-to-speed-upstroke-care/ Accessed 15 Sept 2020

Publisher's note Springer Nature remains neutral with regard to jurisdictional claims in published maps and institutional affiliations. 